\title{
Commentary: Bad biology, or victim of circumstance?
}

\author{
Sandra L. Starnes, MD
}

From the Division of Thoracic Surgery, Department of Surgery, University of Cincinnati College of Medicine,
Cincinnati, Ohio.
Disclosures: Author has nothing to disclose with regard to commercial support.
Received for publication June 23, 2019; accepted for publication June 25, 2019; available ahead of print Aug 13,
2019.
Address for reprints: Sandra L. Starnes, MD, University of Cincinnati College of Medicine, 231 Albert B. Sabin
Way, MC 0558, Cincinnati, OH 45267 (E-mail: sandra.starnes@uc.edu).
J Thorac Cardiovasc Surg 2019;158:e141
0022-5223/\$36.00
Copyright @ 2019 by The American Association for Thoracic Surgery
https://doi.org/10.1016/j.jtcvs.2019.06.090

In this issue of the Journal, Ayub and colleagues ${ }^{1}$ present a case report of a pulmonary hepatoid adenocarcinoma, pathologic stage T1bN0M0, which was treated with surgical resection through a thoracoscopic lobectomy. Despite a complete metastatic workup before surgery, as well as a complete resection with mediastinal lymph node sampling, widespread metastatic disease developed within 3 months of resection. Hepatoid adenocarcinomas rarely occur in the lung, with only 36 reported cases in the literature, as reviewed by Ayub and colleagues. ${ }^{1}$ They also queried the Surveillance, Epidemiology, and End Results (SEER) database from 1988 to 2014, in which interval only 41 cases were reported. Most tumors reported presented at an advanced stage and were associated with poor overall survival. Ayub and colleagues ${ }^{1}$ conclude that these tumors are associated with an aggressive course and very poor prognosis and that a comprehensive evaluation for metastatic disease should be undertaken before surgical resection.

This is a nice case report and review to add to the literature, given the rarity of this tumor and the likely lack of awareness of it among thoracic surgeons. The strength of this article is the use of the SEER database, as well as a review of the available literature, encompassing the largest number of patients with this histologic type.

It is unclear, however, whether the poor outcome of this tumor type is due to an aggressive tumor biology or to the advanced stage at presentation. Only 7 cases in the SEER database were stage I or II, and only 5 of these patients underwent surgical resection. The outcomes of these patients were not available. From their literature review, outlined in the article's supplementary table, at least 8 of the 36 patients were clinical/pathologic stage I/II. All these patients underwent surgery, with 1 also undergoing chemotherapy. Of these 8 patients, 6 are reported as alive, with a follow-

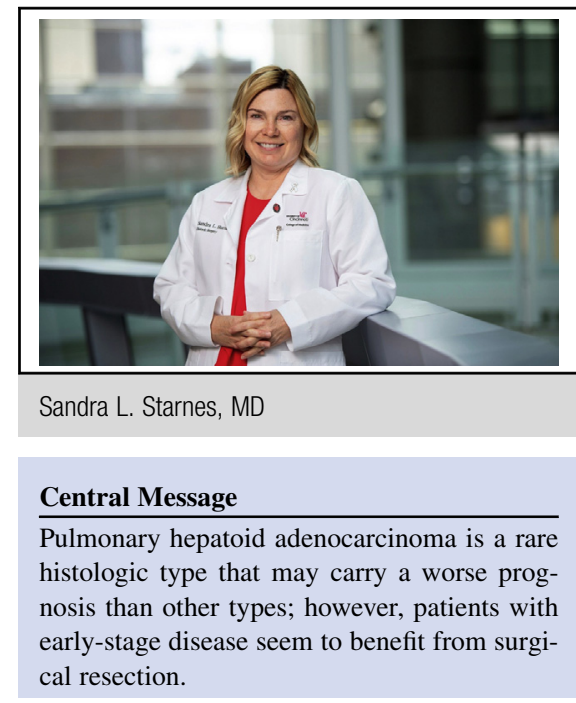

See Article page e139.

up ranging from 5 months to 7 years, and the other 2 have no reported follow-up. In a recent review of 41 patients, 13 patients had stage I/II disease and underwent surgery. ${ }^{2}$ Nine of these 13 were disease free at 5 months to 7 years, 2 had no reported outcomes, and 2 died of disease 2 and 18 months after presentation.

Although this histologic type may appear to be a bad actor, we must interpret this conclusion with caution. We do not have enough evidence that these tumors should be treated any differently from those of other histologic types. All thoracic surgeons have had patients with seemingly early-stage non-small cell lung cancer who have had recurrence months after resection. A critical need is a prognostic test that risk stratifies patients with early-stage lung cancer better than stage alone and is predictive of benefit from adjuvant chemotherapy, such as exists for breast cancer.

\section{References}

1. Ayub A, Nunez Lopez O, Booth A, Okereke I. Pulmonary hepatoid adenocarcinoma. J Thorac Cardiovasc Surg. 2019;158:e139-40.

2. Yang K, Jiang H, Li Q. Primary pulmonary hepatoid adenocarcinoma: a case report and review of the literature. Medicine (Baltimore). 2019;98:e15053. 